\title{
ANATOMICAL BASICS AND VARIATIONS OF THE SCAPULA IN
} SOUTH INDIAN POPULATION

\section{V.Nithya *1, P. Murali ${ }^{2}$, S. Sundarapandian³.}

${ }^{1}$ Assistant Professor, Department of Anatomy, SRM Medical College Hospital and Research Centre, Kattankulathur,Tamilnadu,India.

${ }^{* 2}$ Assistant Professor,Department of Anatomy, SRM Medical College Hospital and Research Centre, Kattankulathur, Tamilnadu, India.

${ }^{3}$ Professor\& HOD, Department of Anatomy, SRM Medical College Hospital and Research Centre, Kattankulathur, Tamilnadu, India.

\section{ABSTRACT}

Introduction: Morphology of suprascapular notch (SSN) and measurement of safe zone for the approach of suprascapular nerve is associated with suprascapular nerve entrapment neuropathy. For better knowledge about different shape and measurement of safe zone for suprascapular nerve distance is important for the clinicians in understanding the source of the entrapment neuropathy and avoiding the nerve injury during operative procedure.

Aim: The aim of the present study is to find out the morphology of suprascapular notch and measurement of safe zone for the suprascapular nerve distance in Indian dry scapula.

Materials and methods: The present study was carried out in 150 adult dried human scapulae of undetermined sex in Indian population. The following parameters were measured, 1. Shape of suprascapular the notch. 2. Measurement of safe zone for the suprascapular nerve distance.

Results: Out of 150 scapulae, 76 (51\%) were shallow U shaped notch, 32 (21\%) were deep U shaped notch, 10 (7\%) were J shaped notch, $12(8 \%)$ were $V$ shaped notch, $12(8 \%)$ showed absence of notch, $8(5 \%)$ showed complete foramen. The mean value of distance between the suprascapular notch and the supraglenoid tubercle (SGT) were 3.10 \pm 0.32 . The mean value of distance between the spinoglenoid notch (SGN) and the posterior rim of glenoid cavity $(P G C)$ were $1.55 \pm 0.23$. The mean value of distance between the suprascapular notch and the spinoglenoid notch were 2.09 \pm 0.29 .

Conclusion: This study will be useful in understanding the importance of suprascapular notch in causing entrapment neuropathy and safe zone distance is of surgical importance in avoiding injuries to the suprascapular nerve during shoulder surgical procedures.

KEY WORDS: - Supra Scpular Notch, Supra Glenoid Tubercle, Spino Glenoid Notch, Posterior rim of Glenoid Cavity.

Corresponding Author: Dr. P.Murali, Assistant Professor,Department of Anatomy, SRM Medical College Hospital and Research Centre, Kattankulathur, Tamilnadu, India.

E-Mail: pmurali.pt@gmail.com

Access this Article online

Quick Response code

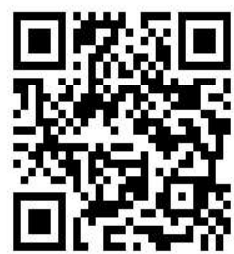

DOI: $10.16965 /$ ijar.2020.149

\begin{tabular}{|c|c|c|}
\hline \multicolumn{3}{|c|}{ Journal Information } \\
\hline 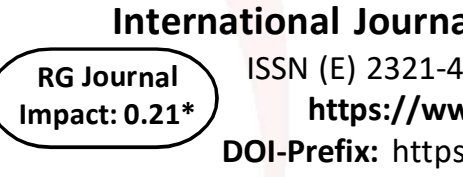 & $\begin{array}{l}\text { Anatomy and Res } \\
\text { ISSN (P) 2321-8967 } \\
\text { hr.org/ijar.htm } \\
\text { doi.org/10.16965/ijar }\end{array}$ & 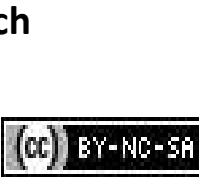 \\
\hline \multicolumn{3}{|c|}{ Article Information } \\
\hline $\begin{array}{l}\text { Received: } 19 \text { Mar } 2020 \\
\text { Peer Review: } 19 \text { Mar } 2020 \\
\text { Revised: None }\end{array}$ & $\begin{array}{l}\text { Accepted: } 20 \mathrm{Apr} \\
\text { Published (O): } 05 \\
\text { Published (P): } 05\end{array}$ & $\begin{array}{l}0 \\
y 2020 \\
2020\end{array}$ \\
\hline
\end{tabular}

\section{INTRODUCTION}

The geometric anatomy of the scapula is of fundamental importance in the pathomechanics of rotator cuff disease, total shoulder arthroplasty, and recurrent shoulder dislocation [1]. The suprascapular notch is a depression on the 
fundamental importance in the pathomechanics superior border of the scapula just medial to the root of coracoid process. Suprascapular notch is converted into suprascapular foramen by the superior transverse scapular ligament. The suprascapular artery passes above the ligament, and the suprascapular nerve passes below the ligament through suprascapular foramen [1].

The superior transverse scapular ligament sometimes ossified and converted into a suprascapular foramen [2-4].Suprascapular nerve is a mixed nerve which gets originated from upper trunk of brachial plexus $(\mathrm{C} 5, \mathrm{C} 6)$. It enters the supraspinous fossa through suprascapular notch and passes deep to supraspinatus muscle and winds around the spinoglenoid notch to reach the infraspinatus fossa and supplies shoulder joint acromioclavicular joint, supraspinatus and infraspinatus which are components of rotator cuff $[5,6]$.Suprascapular notch has been classified by various authors in different populations on the basis ofshape \& diameter of the notch [7-9]. Kopell was the first person to describe the suprascapular nerve entrapment in 1959, he also explains that during abduction at horizontal position of shoulder joint leads to traction on the suprascapular nerve and may compress the nerve against superior transverse scapular ligament [10]. The result of suprascapular nerve entrapment is weakness of arm, difficulty in external rotation and abduction and then atrophy of the infraspinatus and supraspinatus muscles [11-15].

Entrapment neuropathy of suprascapular nerve is more commonly seen in males than in females less than 35 years and it is commonly seen in athletes like volley ball players and baseball pitchers [16].The following factors are involved in the etiology as well as iatrogenic lesions during open or orthroscopic surgical procedures [17-19] - Anterior dislocations of shoulder joint [11] - Injury from direct trauma [11\& 22], ganglionic cyst [20 \& 22]- synovial and swing's sarcoma [21] - chondrosarcoma and lipoma [21]. The glenoid cavity provides a vertical axis for the movement of the head of humerus during abduction and when the arm is raised to the shoulder height, the head slides into the smaller upper part of glenoid cavity which is deepened by glenoid labrum. 3 The variations in the shape and size of glenoid cavity and attachment of glenoid labrum at the glenoid notch are important for normal functioning of this most freely movable joint of the human body [16]. The purpose of this study is to investigate various morphological and morphometric measurements of scapula in south Indian dry scapula.

\section{MATERIALS AND METHODS}

The present study was carried out in 150 adult dried human scapula of undetermined sex in Indian population. Bones with pathological changes and damaged bones were excluded.

The following parameters were measured:

Shape of suprascapular notch:

Measurements of safe zone for the suprascapular nerve distance.

a) Distance between the deepest point of suprascapular notch (SSN) and the supraglenoid tubercle (SGT).

b) Distance between spinoglenoid notch (SGN) and middle of posterior rim of glenoid cavity (PGC).

C) Distance between the deepest part of suprascapular notch (SSN) and spinoglenoid notch (SGN).

Maximum scapular length: Distance from the superior angle to the inferior angle of scapula.

Maximum scapular width: The maximum transverse diameter between the medial border of the scapula, where the spine meets the body of the scapula, and the anterior lip of the glenoid.

Measurement of Scapular Index= (Breadth $\mathrm{X} 100) /$ Length

Superior-Inferior glenoid diameter: Maximum distance measured from the inferior point on the glenoid margin to the most prominent point of the supraglenoid tubercle.

\section{Anterior-Posterior glenoid diameter:}

maximum breadth of the articular margin of the glenoid cavity perpendicular to the glenoid cavity height. Shape of suprascapular notch, Measurement of suprascapular nerve safe zone, scapular index and Glenoid cavity index, was analyzed by student'st-test. The values were expressed as Mean \pm SEM (GRAPH PAD PRISM WINDOW 6 VERSION USA). 
Fig. 1:showing shapes of suprascapular notch and its incidence.A.Shallow ' $U$ ' shapeB.Deep ' $U$ ' shape $C$. ' $J$ ' shape D. ' $V$ ' shape E.Absence of notch F.Complete foramen.

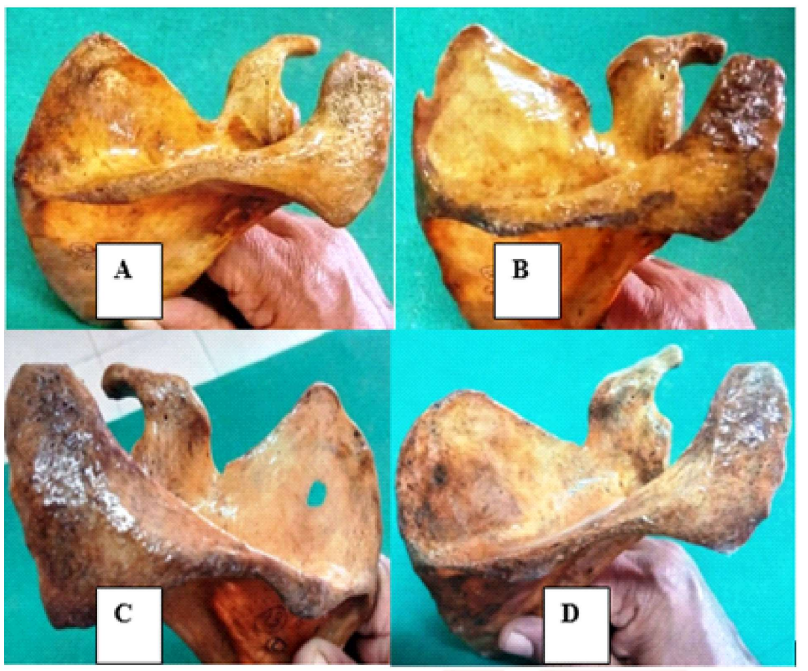

Fig. 2: A. Major Longitudinal Axis of Scapula B. Major transverse axis of scapula C. Major Longitudinal Axis of Glenoid cavity D. Major transverse axis of glenoid cavity.

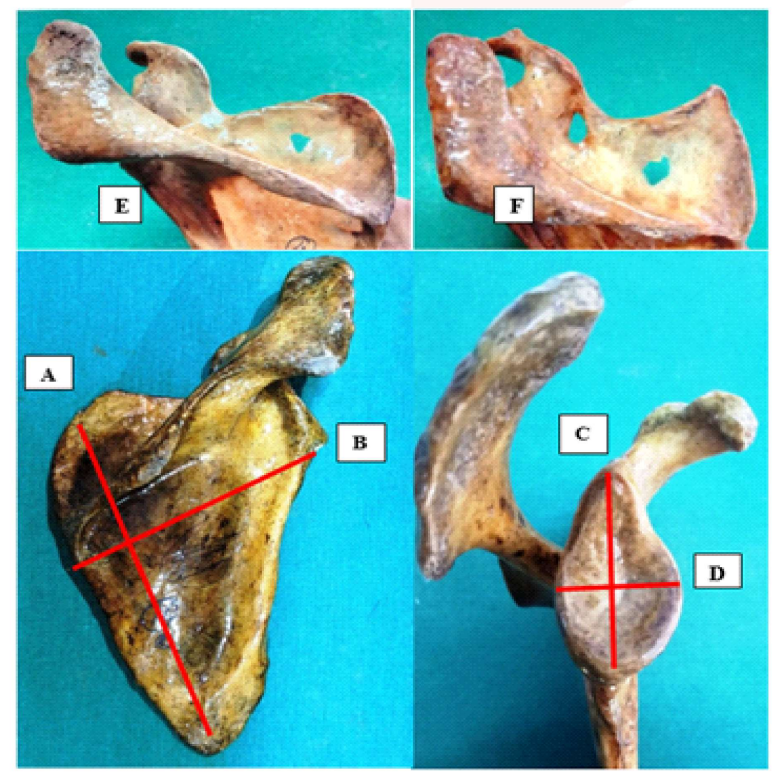

RESULTS

Out of 150 scapulae, 76 (51\%) were shallow ' $U$ ' shaped notch, 32 (21\%) were deep ' $U$ ' shaped notch, 10 (7\%) were ' $\mathrm{J}$ ' shaped notch, 12 (8\%) were ' $V$ ' shaped notch, 12 (8\%) showed absence of notch and $8(5 \%)$ showed complete foramen. Among these all types, Shallow $U$ shape is most common and least common type is the presence of foramen (Table 1).

Measurements of safe zone for the suprascapular nerve distance: the mean value of distance between the suprascapular notch and the supraglenoid tubercle was $3.10 \pm 0.32$. The mean value of distance between the spinoglenoid notch and the posterior rim of glenoid cavity was $1.55 \pm 0.23$. The mean value of distance between the suprascapular notch and the spinoglenoid notch was $2.09 \pm 0.29$ (Table 2).

The mean value of maximum scapular length was $12.5 \pm 1.01$. The mean value of maximum scapular width was $10.2 \pm 0.81$. Measurements of Glenoid cavity: the mean value of superiorinferior glenoid diameterwas $03.4 \pm 0.31$.The mean value of anterior-posterior glenoid diameter was $02.49 \pm 0.30$ (Table 3 ). Measurements of scapular index: the mean value of scapular index was $74.6 \pm 4.18$ (Table 4).

Table 1:showing shapes of suprascapular notch and its incidence.

\begin{tabular}{|c|c|c|c|}
\hline S. No & Shape of the notch & $\begin{array}{c}\text { Number of } \\
\text { notches }\end{array}$ & $\begin{array}{c}\text { Percentage } \\
\text { of notch }\end{array}$ \\
\hline $\mathbf{1}$ & Shallow 'U' shape & 76 & $51 \%$ \\
\hline $\mathbf{2}$ & Deep 'U' shape & 32 & $21 \%$ \\
\hline $\mathbf{3}$ & 'J' shape & 10 & $7 \%$ \\
\hline $\mathbf{4}$ & 'V' shape & 12 & $8 \%$ \\
\hline $\mathbf{5}$ & Absence of notch & 12 & $8 \%$ \\
\hline $\mathbf{6}$ & Complete foramen & 8 & $5 \%$ \\
\hline \multicolumn{2}{r|}{ Total } & 150 & $100 \%$ \\
\hline
\end{tabular}

Table 2:Showing measurements of safe zone for the suprascapular nerve.

\begin{tabular}{|c|c|c|}
\hline S. No & Measurements of safe zone & Mean \pm SD \\
\hline 1 & Distance between SSN and SGT & $3.10 \pm 0.32$ \\
\hline $\mathbf{2}$ & Distance between SGN and PGC & $1.55 \pm 0.23$ \\
\hline 3 & Distance between SSN and SGN & $2.09 \pm 0.29$ \\
\hline
\end{tabular}

Table 3: Various Morphometric Measurements of Scapula.

\begin{tabular}{|c|c|c|c|}
\hline S.No & Parameter Values & $\begin{array}{c}\text { Average } \\
(\mathrm{cm})\end{array}$ & $\begin{array}{c}\text { Mean }(\mathrm{cm}) \text { and } \\
\text { Standard Deviation }\end{array}$ \\
\hline 1 & $\begin{array}{c}\text { Major Longitudinal Axis of } \\
\text { Scapula }\end{array}$ & $10.5-15.8$ & $12.5 \pm 1.01$ \\
\hline 2 & $\begin{array}{c}\text { Major transverse axis of } \\
\text { scapula }\end{array}$ & $08.3-11.7$ & $10.2 \pm 0.81$ \\
\hline 3 & $\begin{array}{c}\text { Major Longitudinal Axis of } \\
\text { Glenoid Cavity }\end{array}$ & $03-04.3$ & $03.4 \pm 0.31$ \\
\hline 4 & $\begin{array}{c}\text { Major transverse Axis of } \\
\text { Glenoid cavity }\end{array}$ & $01.8-03.2$ & $02.49 \pm 0.30$ \\
\hline
\end{tabular}

Table 4: Showing distribution of scapula as per its scapular index (Breadth/length) X100)

\begin{tabular}{|c|c|c|c|}
\hline S.No & $\begin{array}{c}\text { Scapular } \\
\text { index }\end{array}$ & $\begin{array}{c}\text { Number of } \\
\text { scapula }\end{array}$ & $\begin{array}{c}\text { Percentage } \\
\text { (\%) }\end{array}$ \\
\hline $\mathbf{1}$ & $65-70$ & 17 & 11.3 \\
\hline $\mathbf{2}$ & $70-75$ & 68 & 45.3 \\
\hline $\mathbf{3}$ & $75-80$ & 45 & 30.1 \\
\hline $\mathbf{4}$ & $80-85$ & 20 & 13.3 \\
\hline
\end{tabular}




\section{DISCUSSION}

In Indian population the frequency of ossification of superior transverse scapular ligament into a bone resulting conversion of suprascapular notch into a foramen varies from $1.92 \%$ to $10 \%$ krishnagopal et al., [23] and $10 \%$ to $12 \%$ have been reported by Vandhana et al.,[24]and Jadhave et al.,[25].

The present study showed only $5 \%$ of complete ossification of superior transverse scapular ligament converts suprascapular notch into a suprascapular foramen in 150 dry scapulae in Indian population. It was found to be lower in percentage than the earlier reported by Krishna Gopal et al., [23] Vandhanaet al., [24], and Jadhave et al., [25].

The present study observation was significant as compared to those of other studies done on various populations it has been reported to be more in Brazilian (30.76\%) population, followed by Turkish (12.5\%) and American (6.5\%) populations. Paolo Albino et al., 2013 [26] reported that, $1.93 \%$ - $4 \%$ of scapulae showed complete fusion of superior transverse scapular ligament which leads the notch into a foramen. The incidence of complete ossification of the superior transverse scapular ligament was similar with the present study.lqbal et al.,[27] reported three types of suprascapular notch based on the shapes, ' $U$ ', ' $V$ ' and ' $\mathrm{J}$ ' on gross examination. Nafees Fathima et al.,[28] distinguished, the $U$ notch on the basis of depth (shallow and deep) by visual observation.Dunkelgrun et al., [29] reported that the ' $U$ ' shaped notch had a large area than the ' $V$ ' shaped notch, leading to an assumption that the ' $V$ ' shaped notch was more likely to be connected with the nerve entrapment.In the present study, ' $U$ ' shaped notch was more common (shallow ' $U$ ' $-51 \%$,deep ' $U$ ' $-21 \%$ ) than the ' $V$ ' shaped notch (8\%). This study findings was not similar to those of various other studies, Ticker et al., [30] ('U' - 77\%, 'v' - 23\%), Bayramoglu [31] ('U'-62.5\%, 'V'- 25\%), Duparc[32] ('U'-63.3\%, ' $\mathrm{V}$ '- 36.7\%), Muralidharreddysangam et al.,[33] ('U'-69.23\%, 'V'- 26.92\%).

Several morphological variations and classification of the suprascapular notch were reported in many populations (Rengachary et al., 1979;
Iqbal and Khan, 2010; [34, 27] Sinkeet et al., 2010; Wang et al., 2011) [35, 36] All the above studies were based on the morphology of the suprascapular notch and few studies are available on the safe zone approach of suprascapular nerve in order to prevent the iatrogenic injury of the nerve. The safe zone approach of suprascapular notch was reported by various authors, Hafezji 2016 [37] in south Gujarat population, Sabreen 2018 [38] in Egyptian population. These authors examined safe zone distance and reported no significant correlation with dimensions of the suprascapular notch. The distance between the suprascapular notch and the margin of the glenoid cavity is critical during open surgical procedures which require dissection of the posterior shoulder joint, as has been described by De Mulder et al.,[39] and Warner et al., [40]. It has been reported that 2.3 $\mathrm{cm}$, from the glenoid rim, at the level of the superior rim of theglenoid and $1.4 \mathrm{~cm}$, from the posterior rim of the glenoid, at the level of the base of the scapular spine are safe.Another study was carried out by Muralidharreddyet al., [33] reported that the safe zone for the approach of suprascapular nerve during surgical procedures has been described, the mean distance from the glenoid rim, at the level of the superior rim of the glenoid were $2.9 \mathrm{~cm}$ and from the posterior rim of the glenoid, at the level of the base of the scapular spine $1.6 \mathrm{~cm}$ respectively. A similar study were carried out by Sinkeet et al., [35] in the Kenyan population, which described that $5.9 \%$ and $12 \%$ scapulae fell short of the critical distance respectively. In the present study, the mean value of distance between the suprascapular notch and the supraglenoid tubercle was $3.10 \pm 0.32$, when compared with above mentioned populations the present study showed higher values in Indian population and the mean value of distance between the spinoglenoid notch and the posterior rim of glenoid cavity was $1.55 \pm 0.23$, it was in accordance with the above studies. In the present study thiswas the firstofitskind reported that the mean value of distance between the suprascapular notch and the spinoglenoid notch was $2.09 \pm 0.29$ in Indian population.

The Scapular breadth was ranging from $83 \mathrm{~mm}$ to $117 \mathrm{~mm}$ in present study, while other studies 
showed it 83-126 mm [41-44]. The mean scapular breadth in various studies range from 92-104 $\mathrm{mm}$. In present study mean scapular breadth is $102 \mathrm{~mm}$ which is nearer to the study by Von Shroeder 2001[45]. The Scapular length in present study was ranging from $105 \mathrm{~mm}$ to $158 \mathrm{~mm}$ and mean Scapular length was $125 \mathrm{~mm}$ $\pm 1.01 \mathrm{~mm}$,While Flower WH's study of European race showed mean length to be $155.44 \mathrm{~mm}$. Thus, the scapular length of European region and Kashmir region was higher than that of south Indian population (Flower, 1879) [46 \& 47].Mean scapular index observed in present study was $74 \mathrm{~mm}$ with standard deviation of $4.18 \mathrm{~mm}$. In other studies, the mean scapular index ranged from a minimum of $57.3 \mathrm{~mm}$ in Peruvian population to a maximum of $72 \mathrm{~mm}$ in the Negroes and Kashmir region. Thus, our study scapular index value is nearer to Negroes and Kashmir population [47].

Previous studies reported that abnormal morphology of the glenoid was associated with severe full thickness tears [48 \&49]. The length and breadth of glenoid cavity is an important factor which should be appropriately matched with the size of prosthesis during total shoulder arthroplasty in order to achieve full congruency [50\&51]. In the present study the average superior-inferior diameter of the right glenoid was $34 \pm 03.2 \mathrm{~mm}$ and the average anterioposterior diameter of the glenoid was $24.9 \pm 3.0 \mathrm{~mm}$.lannotti et al., reported that superior-inferior diameter of the glenoid to be $39 \pm 3.5 \mathrm{~mm}$ value was more than the when compared to the present study[52]. Mallon et al., and Von Schroeder et al., reported that SI diameter to be $35 \pm 4.1 \mathrm{~mm}$ and $36 \pm 4 \mathrm{~mm}$ respectively [53\&54].

\section{ABBREVIATIONS}

SSN - Supra Scpular Notch

SGT - Supra Glenoid Tubercle

SGN -Spino Glenoid Notch

PGC- Posterior rim of Glenoid Cavity

\section{CONCLUSION}

This study will be useful in understanding thevariations of the scapula, morphometry of glenoid cavity and importance of suprascapular notch in causing entrapment neuropathy; safe zone distance is of surgical importance in avoiding injuries of the suprascapular nerve during shoulder surgical procedures.

\section{ACKNOWLEDGEMENTS}

I am indebted to my colleagues, Dr. S. Pratheepa Sivasankari-(Professor, SRM Medical College Hospital and Research Centre, Kattankulathur, Tamilnadu, India).

\section{Conflicts of Interests: None}

\section{REFERENCES}

[1]. Gray's anatomy. The anatomical basis of clinical practice. Fortieth edition. 793-794.

[2]. Das S, Suri R, Kapur V. Ossification of Superior transverse scapular ligament and its clinical implications. Sultan Qaboos Univ Med J. 2007 ;7(2):15760.

[3]. Khan MA. Complete ossification of the superior transverse scapular ligament in an Indian male adult. Int J Morphol. 2006; 24(2):195-6.

[4]. Peæina M, Krmpotiæ-Nemaniæ J, Markiewitz A. Suprascapular nerve. In: Peæina M, KrmpotiæNemaniæ J, Markiewitz A, eds. Peripheral Nerve Compression Syndromes. 2nd ed. Boca Raton, FL: CRC Press; 1997.

[5]. Vorster W, Lange CP, BriëtRJ, Labuschagne BC, DU Toit DF, Muller CJ, De Beer JF The sensory branch of the suprascapular nerve: An anatomic study. J Shoulder Elbow Surg, 2008; 17(3): 500-502.

[6]. Molony DC, GheitiAJC, Kennedy J, Green C, Schepens A, MullettHJ A cadaveric model for suprascapular nerve injury during glenoid component screw insertion in reverse-geometry shoulder arthroplasty. J Shoulder Elbow Surg,2011; 20(8): 1323-1327.

[7]. Natsis K, Totlis T, Tsikaras P, Appell HJ, Skandalakis K. Proposal for classification of the suprascapular notch: a study on 423 dried scapulas. Clin Anat. 2007; 20:135-9.

[8]. David A. Ofuson, Raymond A. Ude, Cristina U. Okwuonu, Olamide A. Adesanya. Complete absence of the suprascapular notch in Nigerian scapula: a possible cause of suprascapular nerve entrapment. Int J Shoulder Surg. 2008;2(4):65-6.

[9]. Iqbal K, Iqbal R, Khan SG. Anatomical variations in shape of suprascapular notch of scapula. J Morphol Sci. 2010; 27:1-2.

[10]. Kopell HP, Thompson WA. Pain and frozen shoulder. Surg Gynecol Obstet. 1959; 109:92-6.

[11]. Antonoiou J, Tae SK, Wiliams GR, Bird S, Ramsey MJ,lannotti JP. Suprascapular neuropathy. Variabilityin the diagnosis, treatment, and outcome. ClinOrthop Rel Res. 2001; 386:131-8.[5].

[12].Cummins CA, Messer TM, Nuber GW. Suprascapularnerve entrapment. J Bone Join Surg 2000; 82-A: 415-24.[6]. 
V.Nithya, P. Murali, S. Sundarapandian. ANATOMICAL BASICS AND VARIATIONS OF THE SCAPULA IN SOUTH INDIAN POPULATION.

[13].Edeland HG, Zachrisson BE. Fracture of the scapularnotch associated with lesion of the suprascapularnerve. Acta Orthop Scand. 1975;46 (758):763.[7].

[14]. Ferretti A, Cerullo, G, Russo G. Suprascapular neuropathy in volleyball players. The Journal of BoneJoint Surg AM. 1987; 69:260-3.[8].

[15]. Vastamaki M, Goransson GH. Suprascapular nerveentrapment. Clin Orth Rel Res.1993; 297(135):143.

[16]. Antoniadis, G., Richter, HP., Rath, S., Braun, V., Moese,G. Suprascapular nerve entrapment :Experience with28 cases. J Neurosurg 1996; 85(6):1020-1025.

[17]. Rengachary SS, Neff JP, Singer PA, Brackett $\mathrm{CF}$ :Suprascapular entrapmentneuropathy. A clinical, anatomical and comparative study, Part I.Neurosurgery1979; 4:441-446.4.

[18]. Shishido H, Kikuchi S:Injury of the suprascapular nerve in shouldersurgery: An anatomic study.J Shoulder Elbow Surg2001; 10:372-376.

[19]. Burkhart SS, Lo IK, Brady PC:Burkhart's view of the shoulder a cowboy's guideto advanced shoulder arthroscopy.Philadelphia: Lippincott, Williams \&Williams.2006; 111-116: 194-203.6.

[20].Piatt BE, Hawkins RJ, Fritz RC, Ho CP, Wolf E, Schickendantz M:Clinicalevaluation and treatment of spinoglenoid notch ganglion cysts.J Shoulder Elbow Surg2002; 11:600-604.

[21]. Hazrati Y, Miller S, Moore S, Hausman M, FlatowE:Suprascapular nerveentrapment secondary to a lipoma.Clin Orthop2003; 411:124-128.

[22]. Charalambos P. Economides et al. An unusual caseof suprascapular nerve neuropathy: a case report.Journal of Medical Case Reports 2011; 5: 419.

[23]. Krishna Gopal, Alok kumarchoudhary, Jolly Agarwal, Virendra kumar. Variations in suprascapular notch morphology and its clinical importance. Int J Res Med Sci. 2015; 3(1): 301- 306.

[24]. Vandana R, Patil Sudha. Morphometric study of Suprascapular Notch. National Journal of Clinical Anatomy. 2013; 2(3):140-44.

[25]. Jadhave.Malik G, Soni VS, Shukla L, Chabbra S, Gaur N. Morphometric Analysis of the Suprascapular Notch. The Internet Journal of Biological Anthropology. 2012; 5(1).

[26]. Paolo Albino, Stefano Carbone, Vittorio Candela, Valerio Arceri, Anna Rita Vestri, Stefano Gumina. Morphometry of the suprascapular notch correlation with scapular dimensions and clinical relevance. BMC MusculoskelDisord. 2013;14:172.

[27].Iqbal K, Iqbal K, Khan S G. Anatomical variations in shape of suprascapular notch of scapula. J.morphol sci. 2010; 27(1): 1-2.

[28].Natsis K, Totlis T, Tsikaras P, Appell HJ, SkandalakisP, Koebke J Proposal for classification of the suprascapular notch: a study on 423 dried scapulas. Clin Anat. 2007; 20: 135-139.

[29].Dunkelgrun M, Lesaka K, Park SS, Kummer FJ, Zuckkerman JD. Interobserver reliability and intraobserver reproducibility in supra-scapular notch typing. Bull Hosp Joint Dis. 2003; 61: 118-22
[30]. Ticker JB, Djurasovic M, Strauch RJ, April EW Pollock RG, Flatow EL, Bigliani LU. The incidence of ganglion cysts and other variations in anatomy along the course of suprascapular nerve. J Shoulder Elbow Surg. 1998; 7: 472-78.

[31]. Bayramoglu A, Demiryurek D, Tuccar E, Erbil M, Aldur MM, Tetik O, Doral MN. Variations in anatomy at the suprascapular notch possibly causing suprascapular nerve entrapment: an anatomical study. Knee Surg Sport TrumArthros. 2003; 11: 393-98.

[32]. Duparc F, Coquerel D, Ozeel J, Noyon M, Gerometta $\mathrm{A}$, Michot $\mathrm{CH}$. Anatomical basis of the suprascapular nerve entrapment and clinical relevance of the supraspinatus fascia. Surg Rad Anat. 2010; 32: 27784.

[33]. Muralidhar Reddy Sangam, Sattiraju Sri Sarada Devi, Karuman-chi Krupadanam,andKollaAnasuya. A study on the morphology of the suprascapular notch and its distance from the glenoid cavity. J Clin Diagn Res. 2013; 7(2): 189-192.

[34]. Rengachary SS, Burr D, Lucas S, Hassanein KM, Mohn MP, Matzke H. Suprascapular entrapment neuropathy: a clinical, anatomical, and comparative. Study Part 2: anatomical study. Neurosurgery. 1979; 5(4):447-51.

[35]. Sinkeet SR, Awori KO, Odula PO, Ogeng JA, Mwachaka PM. The suprascapular notch: its morphology and distance from the glenoid cavity in a Kenyan population. Folia Morphol. 2010; 69 (4): 241-45.

[36]. Wang HJ, Chen C, Wu LP, Pan CQ, Zhang WJ, Li YK. Variable morphology of the suprascapular notch: an investigation and quantitative measurements in Chinese population. Clin Anat. 2011; 24(1):47-55.

[37]. Hafezji HM. An osteological study of measurement of safe zone to prevent iatrogenic suprascapular nerve injury and its correlation with type of suprascapular notch.Int J Res Med Sci. 2016;4(11):5034-5040

[38]. Sabreen M Ahmed. Morphometry oif suprascapular notch in Egyptian dry scapulae and its correlation with measurements of suprascapular nerve safe zone for clinical consideration. Eur. J. Anat. 2018; 22 (6): 441- 448.

[39]. De Mulder K, Marynissen H, Van Laere C. Arthroscopic transglenoid suture of Bankart lesions. Acta Orthop Belg. 1998; 64 160-66. [6].

[40]. Warner JJP, Krushell RJ, Masquelet A, Gerber C. Anatomy and relationships of suprascapular nerve: anatomical constraints to mobilization of the supraspinatus and infraspinatus muscles in management of massive rotator-cuff tears. J Bone Joint Surg Am. 1992; 74: 36-45.

[41]. Inman, Saunders JB. Abbot. Observation on the junction of the shoulder joint. Journal of bone \& joint surgery. 1944; 1:30.

[42]. Krogman WM, Iscan MY. Determination of Sex and Parturition by scapula, the human skeleton in forensic medicine, 2 nd edition, USA: Charles Thomas publishers. 1986: 135-228.

[43]. Mc Minn, R.M.H 2009. Last's Anatomy. 9th ed. UK edition: Churchill Livingstone. P. 53 
[44]. Montagu. Introduction to Physical Anthropology, 3rd Edition,USA: Charles Thomas publishers; 1960. Page 620-21.

[45]. Von Schroeder HP, Kuirer SD. 2001. Osseous Anatomy of scapula. Journal of Clin OrthopRelat Res; page 313-139.

[46]. Flower WH, Garson JG. The scapular index as a race character in man. Journal of anatphysiol 1879; 14(1): 13-17.

[47]. Maheen Nazir, Bashir Ahmad Shah, Shaheen Shahdad, Basit Aslam and RabiyaAmin,. "Scapular measurements and indices, anobservational study at GMC Srinagar, Kashmir.", International Journal of Current Research. 2018;10 (03): 67125-67128.

[48]. Churchill RS, Brems JJ, Kotchi H. Glenoid size, inclination, and version: an anatomic study. J Shoulder Elbow Surgery.2001;10:327-32

[49]. Kandemir V, Allaire RB, Jolly JT, Debski RE, McMohan PJ. The Relationship between the orientation of the glenoid and tears of the rotator cuff. JBJS. 2006; 88 (8) Aug: 1105-09.
[50]. Poppen NK, Walker PS. Normal and abnormal motion of the shoulder. Journal of Bone and Joint Surgery. 1976; 58A: 195-201.

[51]. Mamatha T, Pai SR, Murlimanju BV, Kalthur SG, Pai MM, Kumar B. Morphometry of Glenoid Cavity. Online Journal Health Allied Sciences. 2011; 10 (3): 7 1-4.

[52].Iannotti JP, Gabriel JP, Schneck SL, Evans BG, MisraS.The normal glenohumeral relationships. An anatomicalstudy of one hundred and forty shoulders.J Bone JointSurg Am 1992;74:491-500.

[53].Mallon WJ, Brown HR, Vogler JB 3rd, Martinez S. Radio-graphic and geometric anatomy of the scapula. Clin Or-thopRelat Res 1992;277:142-154.

[54]. Von Schroeder HP, Kuiper SD, Botte MJ. Osseous anatomy of the scap ula. Clin OrthopRelat Res2001; 383:131-139.

How to cite this article:

V.Nithya, P. Murali, S. Sundarapandian. ANATOMICAL BASICS AND

VARIATIONS OF THE SCAPULA IN SOUTH INDIAN POPULATION.Int J Anat Res 2020;8(2.2):7519-7525. DOI: 10.16965/ij ar.2020.149 